\title{
ANDROGYNY IN ADOLESCENT PSYCHIATRIC PATIENTS AND IN DELINQUENTS
}

\author{
BY \\ A. S. HENDERSON, M.D., M.R.C.P., M.R.A.C.P., D.P.M. \\ Member of the Scientific Staff, Medical Research Council Unit for Research on the Epidemiology of \\ Psychiatric Illness, Edinburgh University Department of Psychiatry, Royal Edinburgh Hospital \\ AND \\ PATRICIA DUGARD, M.A. \\ Member of the Department of Statistics, University of Edinburgh
}

The study reported here forms part of an investigation into the physiological maturity of adolescents with psychiatric illness (Henderson, 1967). The Discriminant Androgyny Score No. 1 (Tanner, 1951, 1962 ) is a measure of the femininity of males or the masculinity of females and may be regarded as an index of the degree of sexual differentiation which an individual undergoes during adolescence. The score is derived from measurements of shoulder and hip width. In adults, men have a mean score of 93 units and women of 78 units, both with a standard deviation of about five (Tanner, 1962). While this provides a high degree of discrimination between the sexes in adulthood, the score does not have this function in prepubertal children. It was expected on a priori grounds that, as boys' shoulders and girls' hips become relatively wide during adolescence, the score would increasingly differentiate between the sexes; and the increase in androgyny score would be greater for boys than for girls. The authors could find no longitudinal studies of changes in androgyny during adolescence to support this assumption. The present study, therefore, required normative data to be found for the teenage years.

A number of studies have indicated that a difference exists between the androgyny scores of normal adults and of psychiatric patients belonging to certain diagnostic categories. These studies referred only to adult material. Coppen (1959) found that when a group of 31 male homosexuals was compared with neurotic and control samples, both the homosexuals and the neurotics had significantly lower scores than the controls; that is, they were more feminine. Rey and Coppen (1959) showed that schizophrenic, neurotic, and depressive patients of both sexes had significantly lower androgyny scores than controls.
Johnson (1965) found that 55 sexually impotent male patients showed a tendency to gynandromorphy when their androgyny scores where compared with healthy males. Kelsey (1965) compared the androgyny scores of schizophrenics with those of their siblings, parents, and controls. For female patients, the mean androgyny score was decreased but for males there was no significant difference. Kelsey has drawn attention to the danger of a possible artefact in work on androgyny: there is an indication that androgyny decreases with age during adulthood in both sexes. In this connexion it should be noted that Rey and Coppen's female controls had a significantly lower mean age $(24 \cdot 1$ years; S.D. $=4 \cdot 1)$ than the means for the schizophrenic and depressive samples $(36 \cdot 1$ years; S.D. $=11 \cdot 0$, and $31 \cdot 0$ years; S.D. $=9 \cdot 8$ respectively).

To date only one study refers to androgyny in childhood and adolescence among psychiatric patients. Dutton (1964) found no differences between 25 psychotic boys and a control group of non-mongol subnormal boys. In the present study, the authors argued that if the Discriminant Androgyny Score is indeed less in certain categories of adult psychiatric patients, it is likely that these individuals will have undergone less sex-specific morphological differentiation during adolescence; that is, that they are morphologically immature in addition to being emotionally ill. A comparison has therefore been made of the development of androgyny in normal and psychiatrically disturbed teenagers. It was appreciated that a cohort of such patients would not be strictly comparable with adult psychiatric patients. It was expected that, if the adult findings were indeed valid, the adolescent patients would fail to differentiate at the same rate as healthy teenagers. 


\section{METHOD}

The Discriminant Androgyny Score No. 1 (Tanner, $1951 ; 1962)$ is derived from the biacromial and biiliac diameters according to the formula: 3 (biacromial diameter $)-1$ (bi-iliac diameter $)=$ Androgyny Score. These diameters were measured with the Harpenden Anthropometer according to the method described by Tanner and Whitehouse (1957).

\section{RELIABILITY}

One of us (A.S.H.) gained experience in anthropometry in the course of the pilot study. He had in addition the benefit of two training sessions from $\mathrm{Mr}$ Reginald Whitehouse at the National Children's Home, Harpenden. Provision was made for tests of reliability to be made at two points in the study: immediately before starting and close to its end. The first exercise allowed one to decide if reliability was high enough for the main study to be started; the second gave an indication of any temporal drift in reliability. For the first measurement, ten boys and ten girls from an approved school were measured twice. The first series of measurements were completed on all persons before repeating the procedure, thus ensuring that the second readings were less open to bias from the author's recall of the first. For the measurement of reliability towards the end of the study, seven boys and eight girls, all psychiatric patients, had duplicate measurements taken as before.

The Pearson correlation coefficients for the two measures were as follows:

Reliability at Start of Study (July, 1966)

$\begin{array}{lcc}\quad \text { Diameter } & \text { Boys (10) } & \text { Girls (10) } \\ \text { Biacromial } & 0.973 & 0.952 \\ \text { Bi-iliac } & 0.950 & 0.926\end{array}$

Reliability at End of Study (May, 1967)

$\begin{array}{lcc}\quad \text { Diameter } & \text { Boys (7) } & \text { Girls (8) } \\ \text { Biacromial } & 0.980 & 0.963 \\ \text { Bi-iliac } & 0.943 & 0.937\end{array}$

\section{MATERIAL}

All subjects fulfilled the following criteria: they were aged 12 to 19 years inclusive at the time of examination; they were resident in the cities of Edinburgh or Aberdeen on the night before the examination; none had had at any time a serious physical illness or disability; the measured I.Q. was over 70. Samples were obtained of psychiatrically ill, delinquent and normal adolescents fulfilling the above criteria.

\section{Patient Sample}

This was made up of those teenagers attending, as in-, out-, or day-patients, the psychiatric hospitals or clinics in Edinburgh and Aberdeen during the period of the study: from July 1, 1966, until June 30, 1967, in Edinburgh, and from September 1, 1966, until April 30, 1967, in Aberdeen. For all patients fulfilling the general criteria for inclusion, a letter was written to both the patient and the parents. In all, 72 per cent. of the total sample was examined: those lost from the study mainly comprised individuals who did not reply to two invitations to attend, but a small number were considered by their psychiatrist to be too disturbed to participate.

For those individuals who fulfilled the general criteria but were not examined, data were collected on age, social class, and diagnosis. There was a tendency for Social Class I patients to be underrepresented and Social Class $V$ to be over-represented in the non-examined group.

The diagnostic composition of the patient sample is shown in Table $\mathrm{I}$.

TABLE I

\begin{tabular}{l|r|r|r|r}
\multicolumn{4}{c}{ DIAGNOSTIC CATEGORIES } \\
\hline \multirow{2}{*}{ Diagnosis } & \multicolumn{2}{|c|}{ Number } & \multicolumn{2}{c}{ Percentage } \\
\cline { 2 - 5 } & Boys & Girls & Boys & Girls \\
\hline Psychosis & 4 & 3 & $4 \cdot 3$ & $4 \cdot 2$ \\
Neurosis & 35 & 41 & $37 \cdot 6$ & $57 \cdot 7$ \\
Behaviour Disorder & 39 & 16 & $41 \cdot 9$ & $22 \cdot 5$ \\
Adolescent Crisis & 5 & 5 & $5 \cdot 4$ & $7 \cdot 0$ \\
Abnormal Personality & 6 & 2 & $6 \cdot 5$ & $2 \cdot 8$ \\
Nil Psychiatric Diagnosis & 4 & 4 & $4 \cdot 3$ & $5 \cdot 6$ \\
\hline \multicolumn{1}{c|}{ Total } & 93 & 71 & $100 \cdot 0$ & $100 \cdot 0$ \\
\hline
\end{tabular}

\section{Control SAmple}

This would ideally have been drawn from a city register, thereby avoiding the bias inherent in a school population after the age of 15 years. The present sample was prepared by a quota sampling technique from six Edinburgh schools and an Edinburgh general practice. These schools were chosen as likely to provide a sample closely similar in social class to the patient sample. Although school classes or forms were selected, subjects were chosen within these by systematic methods, using alphabetically arranged registers. Thus, by taking every third name in a class of thirty pupils, one obtained a sample of ten subjects in whom ethnic bias was unlikely to have been present. Full co-operation was obtained from the teenage pupils and their parents: only one refused to participate. The contact rate in the general practice was only 48 per cent., yielding 22 subjects. The total sample numbered 262 persons (126 boys and 136 
girls). The patient and normal samples are compared for age and social class distribution in Tables II and III. These show that the samples were sufficiently comparable for the present exercise. It should be noted that no control material was obtained from Aberdeen, but there are no known grounds for exexpecting regional differences in androgyny. Furthermore, it had been demonstrated that skeletal maturity was not significantly different at the 5 per cent. level among Edinburgh patients, Edinburgh controls, and Aberdeen patients (Henderson, 1967).

TABLE III

SOCIAL CLASS COMPOSITION OF 165 PATIENTS AND 262 CONTROLS

(Values expressed as percentages)

\begin{tabular}{l|c|c|c|c|c|c|c|c}
\hline \multicolumn{2}{l|}{ Social Class } & I & II & III & IV & V & $\begin{array}{c}\text { Not } \\
\text { known }\end{array}$ & Total \\
\hline \multirow{2}{*}{ Boys } & Patients & $6 \cdot 5$ & $15 \cdot 1$ & $41 \cdot 9$ & $18 \cdot 3$ & $12 \cdot 9$ & $5 \cdot 4$ & $100 \cdot 1$ \\
& Controls & $7 \cdot 1$ & $19 \cdot 0$ & $55 \cdot 6$ & $11 \cdot 9$ & $5 \cdot 6$ & $0 \cdot 8$ & $100 \cdot 0$ \\
\hline \multirow{2}{*}{ Girls } & Patients & $9 \cdot 7$ & $11 \cdot 1$ & $43 \cdot 1$ & $22 \cdot 2$ & $9 \cdot 7$ & $4 \cdot 2$ & $100 \cdot 0$ \\
& Controls & $9 \cdot 6$ & $16 \cdot 2$ & $54 \cdot 5$ & $15 \cdot 4$ & $2 \cdot 9$ & $1 \cdot 5$ & $100 \cdot 1$ \\
\hline \multirow{2}{*}{ Total } & Patients & $7 \cdot 9$ & $13 \cdot 3$ & $42 \cdot 4$ & $20 \cdot 0$ & $11 \cdot 5$ & $4 \cdot 9$ & $100 \cdot 0$ \\
& Controls & 8.4 & 17.6 & $55 \cdot 0$ & $13 \cdot 7$ & $4 \cdot 2$ & $1 \cdot 1$ & $100 \cdot 0$ \\
\hline
\end{tabular}

For Patients $n=164$ (93 boys; 71 girls), and for Controls $n=262$ (126 boys; 136 girls)
Delinquent Sample

Samples of delinquent boys and girls were taken from Dr Guthrie's Schools, Edinburgh. These are Approved Schools catering for delinquent children from the whole of Scotland. In the Approved School for girls, all pupils in the age group 12 to 17 years were asked to participate; there were 27 persons, of whom three declined to take part, which gave an overall contact rate of 89 per cent. among the girls. The 52 boys all agreed to take part. The age and social class distribution of the delinquent sample is shown in Tables IV and V.

TABLE IV

AGE COMPOSITION OF DELINQUENT SAMPLE

\begin{tabular}{|c|c|c|c|c|c|c|}
\hline \multicolumn{2}{|c|}{ Age (yrs) } & $12-13 \cdot 9$ & $14-15 \cdot 9$ & $16-17 \cdot 9$ & $18-20 \cdot 0$ & All Ages \\
\hline Boys & $\begin{array}{l}\text { No. } \\
\text { Percentage }\end{array}$ & $\begin{array}{r}27 \\
51.9\end{array}$ & $\begin{array}{ll}25 & \\
& 48 \cdot 1\end{array}$ & - & - & $\begin{array}{l}52 \\
100 \cdot 0\end{array}$ \\
\hline Girls & $\begin{array}{l}\text { No. } \\
\text { Percentage }\end{array}$ & - & $\begin{array}{l}7 \\
29 \cdot 2\end{array}$ & $\begin{array}{ll}17 & \\
& 70 \cdot 8\end{array}$ & - & $\begin{array}{r}24 \\
100 \cdot 0\end{array}$ \\
\hline Total & $\begin{array}{l}\text { No. } \\
\text { Percentage }\end{array}$ & $\begin{array}{ll}27 & \\
& 35 \cdot 5\end{array}$ & $\begin{array}{ll}32 & \\
& 42 \cdot 1\end{array}$ & $\begin{array}{ll}17 & \\
& 22 \cdot 4\end{array}$ & - & $\begin{array}{l}76 \\
100 \cdot 0\end{array}$ \\
\hline
\end{tabular}

TABLE II

AGE COMPOSITION OF PATIENT AND CONTROL SAMPLES (PER CENT.)

\begin{tabular}{|c|c|c|c|c|c|c|c|}
\hline \multicolumn{2}{|c|}{ Age (yrs) } & $\begin{array}{c}12-13.9 \\
\text { (inclusive) }\end{array}$ & $14-15 \cdot 9$ & $16-17 \cdot 9$ & $18-20 \cdot 0$ & All Ages & $\begin{array}{c}\text { Total } \\
\text { Numbers }\end{array}$ \\
\hline Boys & $\begin{array}{l}\text { Patients } \\
\text { Controls }\end{array}$ & $\begin{array}{l}25 \cdot 8 \\
21 \cdot 4\end{array}$ & $\begin{array}{l}34 \cdot 4 \\
34 \cdot 9\end{array}$ & $\begin{array}{l}17 \cdot 2 \\
30 \cdot 2\end{array}$ & $\begin{array}{l}22 \cdot 6 \\
13 \cdot 5\end{array}$ & $\begin{array}{l}100 \cdot 0 \\
100 \cdot 0\end{array}$ & $\begin{array}{r}93 \\
126\end{array}$ \\
\hline Girls & $\begin{array}{l}\text { Patients } \\
\text { Controls }\end{array}$ & $\begin{array}{l}23 \cdot 6 \\
21 \cdot 3\end{array}$ & $\begin{array}{l}30 \cdot 6 \\
36 \cdot 0\end{array}$ & $\begin{array}{l}29 \cdot 2 \\
36 \cdot 0\end{array}$ & $\begin{array}{r}16 \cdot 7 \\
6 \cdot 6\end{array}$ & $\begin{array}{r}100 \cdot 1 \\
99 \cdot 9\end{array}$ & $\begin{array}{r}71 \\
136\end{array}$ \\
\hline Total & $\begin{array}{l}\text { Patients } \\
\text { Controls }\end{array}$ & $\begin{array}{l}24 \cdot 9 \\
21 \cdot 4\end{array}$ & $\begin{array}{l}32 \cdot 7 \\
35 \cdot 5\end{array}$ & $\begin{array}{l}22 \cdot 4 \\
33 \cdot 2\end{array}$ & $\begin{array}{r}20 \cdot 0 \\
9.9\end{array}$ & $\begin{array}{l}100 \cdot 0 \\
100 \cdot 1\end{array}$ & $\begin{array}{l}164 \\
262\end{array}$ \\
\hline
\end{tabular}

TABLE V

SOCIAL CLASS OF DELINQUENT SAMPLE

\begin{tabular}{|c|c|c|c|c|c|c|c|c|}
\hline \multicolumn{2}{|c|}{ Social Class } & \multirow{2}{*}{$\begin{array}{r}\text { I } \\
-\end{array}$} & II & III & IV & $\mathbf{V}$ & Not known & Total \\
\hline Boys & $\begin{array}{l}\text { No. } \\
\text { Percentage }\end{array}$ & & 1 & 10 & $32 \cdot 7$ & 26.9 & 10 & 52 \\
\hline Girls & $\begin{array}{l}\text { No. } \\
\text { Percentage }\end{array}$ & - & - & $20 \cdot 8$ & $33 \cdot 3$ & $20 \cdot 8$ & $25 \cdot 0$ & 24 \\
\hline Total & $\begin{array}{l}\text { No. } \\
\text { Percentage }\end{array}$ & - & $1 \cdot 3$ & $19 \cdot 7$ & $32 \cdot 9$ & $25 \cdot 0$ & 16 & $100 \cdot 0$ \\
\hline
\end{tabular}



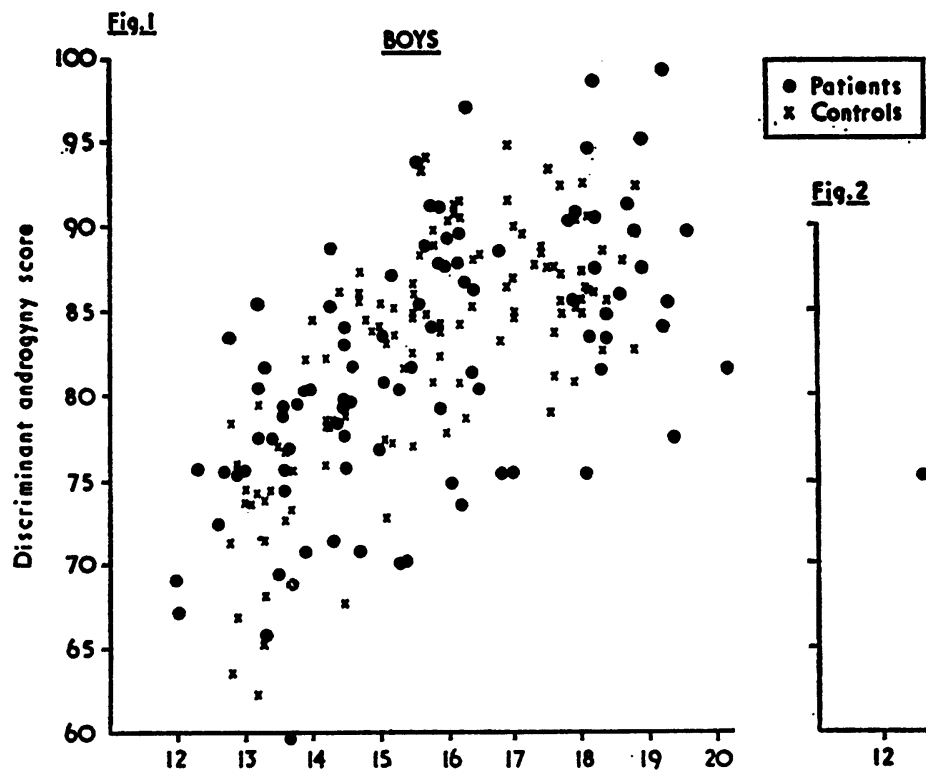

\section{Age (yrs)}

FIG. 1.- "Scatter-diagram" of Androgyny in boys.

\section{ANALYSIS AND FINDINGS}

For patients and normal subjects graphs were prepared for each sex showing the change in androgyny with age (Figs 1 and 2).

Over the age range considered, and this is emphasized, the distribution of androgyny against chronological age was approximately linear, so regression lines were fitted for the diagnostic groups which were large enough (Neurotic and Behaviour Disorder), for the delinquents, and for the controls. It was appreciated at the same time that the androgyny score is likely to approach a fairly constant value at the end of adolescence. The apparent linearity in the graphs was thought to be a function of the limited age range studied. The true regression line, therefore, was almost certain to be curvilinear, but for the purpose of this comparative study it was legitimate to compare the slope of linear regression in normal subjects and in patients. To compare the normal subjects with the total patient group, an F-test (Lindley, 1965) was applied to see if the ordinates were different in either sex, and if the slopes were different in either sex (Table VI).

No significant differences were found. The least squares estimate of the regression coefficients ( 95 per
TABLE VI

COMPARISON OF ANDROGYNY IN PATIENTS (EXCLUDING DELINQUENTS) AND NORMALS

\begin{tabular}{|c|c|c|c|c|c|}
\hline Sex & Comparison & $\begin{array}{l}\text { Sums of } \\
\text { Squares }\end{array}$ & $\begin{array}{l}\text { Degrees of } \\
\text { Freedom }\end{array}$ & $\begin{array}{l}\text { Mean } \\
\text { Squares }\end{array}$ & $\mathbf{F}$ \\
\hline \multirow{5}{*}{ Boys } & Between ordinates & $70 \cdot 547$ & 1 & $70 \cdot 547$ & $2 \cdot 16$ \\
\hline & Between slopes & $37 \cdot 232$ & 1 & $37 \cdot 232$ & $1 \cdot 14$ \\
\hline & Residual & 7020.999 & 215 & $32 \cdot 656$ & \\
\hline & Ordinates residual & $7058 \cdot 231$ & 216 & $32 \cdot 677$ & \\
\hline & Total & $7128 \cdot 784$ & 217 & & \\
\hline \multirow{5}{*}{ Girls } & Between ordinates & $50 \cdot 026$ & 1 & $50 \cdot 026$ & $2 \cdot 12$ \\
\hline & Between slopes & $14 \cdot 357$ & 1 & $14 \cdot 357$ & 0.61 \\
\hline & Residual & $4798 \cdot 334$ & 203 & $23 \cdot 637$ & \\
\hline & Ordinates residual & $4812 \cdot 691$ & 204 & $23 \cdot 592$ & \\
\hline & Total & $4862 \cdot 717$ & 205 & & \\
\hline
\end{tabular}

cent. confidence intervals) for the combined normal and patient group were:

Boys: $\quad \hat{\alpha}=82 \cdot 273 \pm 0.759$

$$
\hat{\beta}=2 \cdot 477 \pm 0.390
$$

Girls: $\quad \hat{\alpha}=77.196 \pm 0.663$

$$
\hat{\beta}=1 \cdot 106 \pm 0.372
$$

(The form $y=\alpha+\beta(x-\bar{x})$ was used) 
Separate regression lines were fitted for the diagnostic categories which were large enough (Neurotics and Behaviour Disorder) and for the delinquents and controls. The F-test for difference in ordinates and in slopes was applied for each sex. There were no significant differences (Table VII).

TABLE VII

COMPARISON OF ANDROGYNY IN TWO DIAGNOSTIC GROUPS, DELINQUENTS AND CONTROLS

\begin{tabular}{l|l|r|c|c|c}
\hline \multirow{4}{*}{ Sex } & \multicolumn{1}{|c|}{ Comparison } & $\begin{array}{c}\text { Sums of } \\
\text { Squares }\end{array}$ & $\begin{array}{c}\text { Degrees of } \\
\text { Freedom }\end{array}$ & $\begin{array}{c}\text { Mean } \\
\text { Squares }\end{array}$ & F \\
\hline \multirow{4}{*}{ Boys } & Between ordinates & $149 \cdot 421$ & 3 & $49 \cdot 807$ & $1 \cdot 55$ \\
\cline { 2 - 6 } & Between slopes & $33 \cdot 018$ & 3 & $11 \cdot 006$ & $0 \cdot 34$ \\
\cline { 2 - 6 } & Residual & $7923 \cdot 583$ & 244 & $32 \cdot 474$ & \\
\cline { 2 - 6 } & Ordinates residual & $7956 \cdot 601$ & 247 & $32 \cdot 213$ & \\
\cline { 2 - 6 } & Total & $8106 \cdot 023$ & 250 & & \\
\hline \multirow{4}{*}{ Girls } & Between ordinates & $100 \cdot 534$ & 3 & $33 \cdot 511$ & $1 \cdot 48$ \\
\cline { 2 - 6 } & Between slopes & $83 \cdot 001$ & 3 & $27 \cdot 667$ & $1 \cdot 22$ \\
\cline { 2 - 6 } & Residual & $4729 \cdot 786$ & 209 & $22 \cdot 631$ & \\
\cline { 2 - 6 } & Ordinates residual & $4812 \cdot 787$ & 212 & $22 \cdot 702$ & \\
\cline { 2 - 6 } & Total & $4913 \cdot 322$ & 215 & & \\
\hline
\end{tabular}

Note: The apparent discrepancy in degrees of freedom is due to a small number of patients in several diagnostic categories not included in this comparison.

From the present material, therefore, the authors have been unable to demonstrate differences in androgyny between psychiatrically ill, delinquent, and normal adolescents.

\section{CONCLUSIONS}

The findings of this study are at variance with those of earlier ones referring to adult psychiatric patients. The following interpretations are offered:

(1) Because of imperfections in the control material, the adult findings are to be held in doubt. There may be no significant differences between the androgyny of adult psychiatric and normal subjects in either sex.

(2) The present findings may fail to show a difference which does exist.

(3) Both the earlier and the present findings may be valid: differences in androgyny may become apparent only in adult psychiatric patients.

Until differences in androgyny among adult psychiatric patients are confirmed by other studies, one may conclude for the present that adolescent psychiatric patients, who may be derived from a different population from their mentally-ill elders, show no abnormality of androgyny. In this area of sexual differentiation, both patients and juvenile delinquents show no differences from behaviourallynormal adolescents. This finding is consistent with other parts of the overall study (Henderson, 1967, 1968) which has demonstrated that physiological maturity, as determined by skeletal age and age at menarche, is the same in mentally-ill, delinquent, and normal adolescents.

For much guidance and helpful criticism, it is a pleasure to thank Professors G. M. Carstairs and D. J. Finney, and Dr Norman Kreitman. The study took place with the help of the following: the teenagers themselves; Dr George Reith, Director of Education in the city of Edinburgh; the Scottish Education Department; Prof. Richard Scott and his staff in the University Department of General Practice; the Mother Superior of the Convent of the Good Shepherd, Colinton; Dr Henry Matthew of the Poisoning Treatment Centre, Edinburgh Royal Infirmary; and the psychiatrists at the several hospitals and clinics in Edinburgh and Aberdeen. Prof. J. M. Tanner and $\mathbf{M r}$ Reginald Whitehouse of the Institute of Child Health, London, gave generously of their experience. Miss Susan Bucher and Mrs Ruth Hannah provided invaluable secretarial and administrative help throughout.

This communication is based on part of the work carried out in the preparation of a thesis submitted (by A.S.H.) in partial fulfilment of the requirements for the degree of M.D. in the University of Aberdeen.

\section{REFERENCES}

Coppen, A. J. (1959). Brit. med. J.. 2, 1443 (Body-build of male homosexuals).

Dutton, G. (1964). Brit. J. Psychiat., 110, 101 (The growth pattern of psychotic boys).

Henderson, A. S. (1967). "The Physiological Maturity of Adolescents with Psychiatric Illness." Unpublished M.D. Thesis, University of Aberdeen.

- (1968). "Physiological Maturity in Adolescent Psychiatric Patients, Juvenile Delinquents, and Normal Teenagers." (In preparation.)

Johnson, J. (1965). Brit. med. J., 2, 572 (Androgyny and disorders of sexual potency).

Kelsey, F. D. (1965). Brit. J. Psychiat., 111, 1159 (Androgyny in schizophrenics and their relatives).

Lindley, D. V. (1965). "Introduction to Probability and Statistics from a Bayesian Viewpoint." Part 2: Inference. University Press, Cambridge.

Rey, J. H., ant Coppen, A. J. (1959). Brit. med. J., 2, 1445 (Distribution of androgyny in mental patients).

Tanner, J. M. (1951). Lancet, 1, 574 (Current advances in the study of physique).

(1962). "Growth at Adolescence", 2nd ed. Blackwell, Oxford.

- and Whitehouse, R. H. (1957). Amer. J. phys. Anthrop., n.s. 15, 277 (The Harpenden anthropometer: a counter-type anthropometric caliper). 